\title{
Rates of HBV, HCV, HDV and HIV type 1 among pregnant women and HIV type 1 drug resistance-associated mutations in breastfeeding women on antiretroviral therapy
}

Judith N. Torimiro ${ }^{\text {* }}$, Aubin Nanfack², William Takang ${ }^{3}$, Claude Kalla Keou ${ }^{4}$, Awum Nchenda Joyce ${ }^{5}$, Kevin Njefi ${ }^{4}$, Kimbong Agyingi ${ }^{4}$, Irenee Domkam ${ }^{6}$, Desire Takou', Sylvie Moudourou', Samuel Sosso ${ }^{8}$ and Robinson E. Mbu ${ }^{4}$

\begin{abstract}
Background: HBV, HCV, HDV and HIV are blood borne and can be transmitted from mother-to-child. Reports of HBV infection rates show up to $11.9 \%$ in Cameroon while for $\mathrm{HCV}$, the rate is less than $2 \%$. More so, as pregnant women get enrolled in the HIV PMTCT Programme and stay in the care continuum, selection of HIV-1 drug resistant strains is evident. We sought to determine the seroprevalence of HBV, HCV, HDV and HIV among pregnant women, assess their knowledge, attitudes and practices on transmission and prevention of HBV infection, and determine HIV drug resistance profile of breastfeeding women.

Methods: A serosurvey of HBV, HCV, HDV and HIV was carried out among 1005 pregnant women in Yaounde, Cameroon. In 40 HIV-infected breastfeeding women enrolled in the PMTCT Programme, HIV-1 genotypes and HIV-1 resistance to NRTIS, NNRTIs and PIs, were determined by phylogeny and the Stanford University HIV Drug Resistance interpretation tool, respectively.

Results: Among the pregnant women, the rates of HIV-1, HBV, HCV and HDV infections were 8.5, 6.4, 0.8 and 4.0\%, respectively. About $5.9 \%$ of the women knew their HBV status before pregnancy unlike $63.7 \%$ who knew their HIV status. Although $83.3 \%$ reported that vaccination against HBV infection is a method of prevention, and $47.1 \%$ knew that HBV could be transmitted from mother-to-child, only $2.5 \%$ had received the Hepatitis B vaccine. Of the 40 women on antiretroviral therapy (ART), 9 had at least one major resistance-associated mutation (RAM, 22.5\%) to NRTI, NNRTI or PI. Of these M184 V (12.5\%), K70R (10.0\%), K103 N (12.5\%), Y181C (10.0\%), M46 L (2.5\%) and L90 M (2.5\%) were most frequently identified, suggesting resistance to lamivudine, nevirapine, efavirenz and zidovudine. Eighty four percent were infected with HIV-1 recombinant strains with CRF02_AG predominating (50\%).

Conclusions: The rates of HBV and HIV-1 infections point to the need for early diagnosis of these viruses during pregnancy and referral to care services in order to minimize the risk of MTCT. Furthermore, our results would be useful for evaluating the HIV PMTCT Programme and Treatment Guidelines for Cameroon.
\end{abstract}

Keywords: HBV, HCV, HDV, HIV, Mother, Child, Transmission, Vaccination, PMTCT, Drug resistance

\footnotetext{
* Correspondence: jn.torimiro@gmail.com

${ }^{1}$ Chantal Biya International Reference Centre for Research on Prevention and

Management of HIV/AIDS (CIRCB), Molecular Biology Laboratory, B.P. 3077,

Messa, Yaounde, Cameroon

Full list of author information is available at the end of the article
}

(c) The Author(s). 2018 Open Access This article is distributed under the terms of the Creative Commons Attribution 4.0 International License (http://creativecommons.org/licenses/by/4.0/), which permits unrestricted use, distribution, and reproduction in any medium, provided you give appropriate credit to the original author(s) and the source, provide a link to the Creative Commons license, and indicate if changes were made. The Creative Commons Public Domain Dedication waiver (http://creativecommons.org/publicdomain/zero/1.0/) applies to the data made available in this article, unless otherwise stated. 


\section{Background}

Hepatitis B Virus (HBV), Hepatitis C Virus (HCV), Hepatitis delta virus (HDV) and Human Immunodeficiency Virus Type 1 (HIV-1) are blood borne and can be transmitted from mother to child. Africa bears about two-thirds of the global HIV burden [1] with women of child-bearing age at higher risk of infection. While the tide of HIV infection is increasing in many countries in sub Saharan africa, Cameroon records a rate of $4.1 \%$ in 2015 , and HBV infection rate of 4.3 to $11.9 \%[2,3]$ and $28 \%$ of $\mathrm{HBeAg}$ [2] among pregnant women. Children born of $\mathrm{HBeAg}$-positive mothers have a $45.5 \%$ chance of infection if no prevention intervention is offered [4] while only $10.2 \%$ may get infected if cesarean section is offered and $28.0 \%$ if by vaginal delivery [5]. We however lack accurate and recent epidemiologic data on HCV infection among pregnant women in Cameroon although low rates have been reported in the early 2000. Meanwhile, HCV RNA-positivity has been associated with the risk of vertical transmission, contributing to a rate of transmission of 4 to $5 \%$. The risk becomes greater if the mother is co-infected with HIV. On the other hand, HDV infects 15 to 20 million people worldwide. In a rural District in northern Cameroon, anti-HDV prevalence of $7.3 \%$ among pregnant women was reported [6] and among adults in Yaounde, 22.7\% [7].

Despite this burden and available information on modes of transmission and prevention of these viruses, prevention and control efforts have not been optimal in low- and middle- income countries (LMIC). To promote the WHO initiative to eliminate viral hepatitis by 2030 , the incorporation of other communicable diseases in the ongoing HIV and Syphilis Prevention of Mother-to-child Transmission (PMTCT) Programmes is imperative [8]. The HIV PMTCT Programme is integrated into the Mother-Newborn and Infant Service in Cameroon, with coverage from 68 to $92 \%$, while the National Early Infant Diagnosis (EID) is at $48 \%$. In spite of the services available for pregnant women at the antenatal clinic (ANC), first antenatal consultation was at $76 \%$ in 2016 with $88 \%$ of the women who knew their HIV status and of whom $8 \%$ were tested at the time of labour.

The AIDS Treatment Guidelines for Cameroon do not incorporate HIV-1 drug resistance (DR) testing at initiation of ART for the pregnant women nor the infants enrolled in the PMTCT Programme. Therefore, the impact of ART in pregnancy and on future therapeutic response of the mother or infant, has not been fully studied. In 2016, 75.7\% of pregnant women were on antiretroviral therapy (68.9\% of the Centre Region where Yaoundé is situated). In spite of these interventions, a rate of $5.6 \%$ of vertical transmission was reported with mother and infant receiving antiretroviral (ARV) drugs [9].
Resistance to nucleoside and nucleotide reverse transcriptase inhibitors (NRTIs) and non-nucleoside reverse transcriptase inhibitors (NNRTIs) can occur in infants who become infected with HIV in spite the ARV-based interventions. In the KiBS study carried out in Kenya, $67 \%$ of infants who were infected despite maternal triple prophylaxis, had drug resistant HIV-1 strains, while in Cameroon a rate of transmitted drug resistance (TDR) of $7 \%$ in treatment-naïve pregnant women was reported [10].

The scope of HBV, HCV, HDV or HIV infection in pregnant women needs to be better understood for resources to be allocated to scale-up the PMTCT Programme and improve the quality of life of infants exposed and/or infected with these viruses. The aims of this study were therefore to determine the seroprevalence of HBV, HCV, HDV and HIV, assess knowledge and attitudes of pregnant women on HBV transmission and prevention, and determine the profile of HIV-1 drug resistance among breastfeeding women who were involved in the PMTCT Programme in Yaoundé, the capital city of Cameroon.

\section{Methods}

Ethical approval to carry out these studies were obtained from the Chantal Biya International Reference Centre for Research on Prevention and Management of HIV/ AIDS (CIRCB) Institutional Review Board (IRB).

\section{Selection of study sites and study participants}

From September 2011 to April 2015, we conducted a cross-sectional study in the antenatal consultation Departments of three tertiary hospitals in Yaoundé, Cameroon. Two groups of women were recruited for these sub studies.

Virus Seroprevalence, and Knowledge, Attitude and Practice (KAP) Survey among Pregnant Women sub Study (Group 1): we used a formula to estimate a population proportion with specified absolute precision. The confidence level was $95 \%$ and a prevalence of $2.5 \%$ of $\mathrm{HCV}$ (which is the least compared to the HIV-1, HBsAg or HDV) were used to calculate the sample size of pregnant women. With an absolute precision of $1 \%$, we calculated a sample size of 937 and added $10 \%$ for missing data, giving a final sample size of 1030 of women of age above 21 years. We however, recruited 1005 within the study period.

HIV Drug Resistance among Breastfeeding Women on Antiretroviral Therapy (ART) sub Study (Group 2): out of 85 HIV-infected women detected in the Group $1 \mathrm{sub}$ study, 50 were enrolled in the PMTCT Programme. They were HBV-negative, HCV-negative, and breastfeeding (for at least 6 weeks) and on ART. Of these, 40 
samples were successfully sequenced for prediction of HIV-1 drug resistance or susceptibility.

\section{Data collection and analysis}

Following a written informed consent, a questionnaire (Additional file 1) was used to collect demographic data, knowledge, attitude, and practices relating to HBV transmission and prevention (Group 1). While in Group 2, data on AIDS treatment history were collected from the participants' hospital records. The data from the questionnaire were analyzed using the EPI Info 7.2 software. The data was summarized using means and standard deviation for quantitative variables and frequencies for qualitative variables. Associations between qualitative variables were done using Fisher's Exact test and the significance level was $5 \%$.

Screening for hepatitis B virus, hepatitis C virus, hepatitis delta virus and HIV infections

HIV-1 antibodies were detected in plasma samples using 2 rapid tests and samples with discordant results were further tested using a fourth generation ELISA (Genscreen ULTRA HIV Ag-Ab). Similarly, the women were screened for HBsAg, HBeAg, anti-HBe, anti-HBc, anti-HCV, anti-HDV by ELISA (Monolisa ${ }^{\mathrm{ms}}$ ). The women diagnosed positive for any of the viruses were interviewed on the awareness of their serological status, and referred to Care services.

\section{Measurement of T lymphocyte CD4 level, plasma HIV-1 RNA load and determination of HIV-1 drug resistance}

$\mathrm{T}$ lymphocyte $\mathrm{CD} 4^{+}$cell counts were determined by flow cytometry using the BD FACScalibur ${ }^{\mathrm{TN}}$ cytometer [11] and plasma HIV-1 RNA load using the Abbott RealTime HIV-1 assay [12]. To determine specific mutations associated to drug resistance in the protease-reverse transcriptase regions of HIV-1 and genotyping, RNA extraction was done from plasma using QIAamp viral RNA mini kit [13], amplified over a 1197 base pair (bp) fragment and sequenced directly as previously described [14] using the Applied BioSystems Model 3130XL Genetic Analyzer [15].

All nucleotide sequences were automatically aligned with reference sequences of all known HIV-1 Group M subtypes and predominant circulating recombinant forms (CRFs) from the Los Alamos HIV sequence database using CLUSTAL $\mathrm{X}$ with minor manual adjustments [16]. Phylogenetic analyses were conducted using the MEGA software package, and trees were constructed by the neighbor-joining method. The protease-reverse transcriptase DNA sequences were analyzed for mutations associated to drug-resistance using the Stanford University HIV Database genotypic resistance interpretation algorithm [17].

\section{Results}

\section{I) General Characteristics of Study Population}

Overall, 1005 pregnant women (Group 1) were included in this study, of age range from 18 to 43 years (mean age of $27.49 \pm 5.18$ years). A majority of the women were in the third trimester (69.9\%) and the gestational age ranged from 6 to 42 weeks with a mean of $29.49 \pm 7.39$ weeks. Multigravid women were the most represented (68.3\%), and gravidity ranged from 1 to 8 pregnancies (Table 1 ).

Over $50 \%$ of the HIV-infected women were diagnosed for HIV infection during pregnancy at their visit to the antenatal clinic. Of these, 36\% were tested during the last pregnancy and 19\% during prior pregnancies while $45 \%$ were tested during Voluntary Testing and Counselling Campaigns.

Group 2 consisted of 50 HIV-infected and breastfeeding women on ART of mean age of 30 ( \pm 4 years), with $50 \%$ married. Of these 50 , only 40 specimens were analyzed for HIV-1 genotypic drug resistance. All the women were on zidovudine plus lamivudine plus nevirapine (AZT + 3TC + NVP) (Table 2).

\section{II) Knowledge, Attitudes and Practices relating to Hepatitis B Virus Infection}

Among women infected with HBV, 5.9\% were aware of their status before pregnancy whereas $63.8 \%$ of those infected with HIV had known their status before pregnancy (Table 3). Whereas, among the women co-infected, 75\%

Table 1 Demographic data of Pregnant Women (Group 1; $N=1005)$

\begin{tabular}{ll}
\hline Characteristics & Value \\
\hline Mean age & $27.49 \pm 5.18$ years \\
Mean gestational age (at 3rd trimester) & $29.49 \pm 7.39$ weeks \\
Mean gravidity & $2.56 \pm 1.47$ pregnancies \\
Multigravid & $68.3 \%$ \\
Marital status & Frequency (\%) \\
Married & 62.1 \\
Cohabitation & 20.2 \\
Single & 17.8 \\
Educational Level & Frequency (\%) \\
Secondary school level & 57.3 \\
Higher level & 31.6 \\
Profession & Frequency (\%) \\
Jobless & 35.8 \\
Self-employed & 18.1 \\
Student & 23.3 \\
\hline
\end{tabular}


Table 2 Demographic data of HIV-infected and Breastfeeding Women on ART (Group 2; N=40)

\begin{tabular}{ll}
\hline Characteristics & Value \\
\hline Mean age & $30 \pm 4$ years \\
Marital status & Frequency (\%) \\
$\quad$ Married & 50 \\
Educational level & Frequency (\%) \\
$\quad$ Secondary school level & 58 \\
Gravidity & \\
Modal gravidity & 2 \\
Modal parity & 2 \\
HAART onset & Frequency (\%) \\
Before last pregnancy & 62.5 \\
During last pregnancy & 17.5 \\
During current pregnancy & 20 \\
HAART regimen & \\
AZT + 3TC + NVP & 100
\end{tabular}

AZT: zidovudine

3TC: lamivudine

NVP: nevirapine

of them had known only about their HIV serological status and not the other virus. Most of the infected women were single with a high mean gravidity compared to those not infected with any of the viruses $(p<0.05)$.

The most common method of transmission of HBV reported by the women was blood transfusion (51.5\%), while

Table 3 KAP Survey on HBV Transmission and Prevention Methods

\begin{tabular}{ll}
\hline & Frequency (\%) \\
\hline Awareness of mode of HBV transmission & 47.1 \\
Mother-to-child & 51.5 \\
Blood transfusion & 39.5 \\
Sharing of personal objects & 47.8 \\
Sexual intercourse & 30.8 \\
Direct contact with body fluid of an infected & \\
individual & \\
Awareness of HBV prevention methods & 37.4 \\
Usage of personal objects & 23.7 \\
Fidelity & 22.5 \\
Abstinence & 83.3 \\
Vaccination & 30.4 \\
Condom use & \\
Awareness of virus serologic status before study & 63.8 \\
HIV & 5.9 \\
HBV & 0 \\
HCV & 2.5 \\
\hline HBV vaccination &
\end{tabular}

47.1 and $47.8 \%$ knew that HBV could also be transmitted from mother-to-child and through sexual intercourse, respectively. More so, 23.7 and $22.5 \%$ reported that HBV can be prevented if fidelity is practiced within married couples, and the use of condoms, respectively. Although $83.3 \%$ of the women admitted that vaccination was a means of preventing HBV infection, it was found that only $2.5 \%$ had received the hepatitis $B$ vaccine (Table 3 ).

\section{III) Seroprevalence of HIV-1, HBV, HCV and HDV in Pregnant Women}

Overall, $15.0 \%(151 / 1005)$ of the women were monoinfected for either HIV-1, HBV or HCV. Rate of HCV infection was $0.8 \%$, of $\mathrm{HBV}(\mathrm{HBsAg}+$ ) was 6.4 , and $8.5 \%$ for HIV-1 (Table 4). No cases of $\mathrm{HBV}$ and $\mathrm{HCV}$ co-infection were identified while $0.1 \%$ (1/1005) was co-infected with HIV-1 and HCV. The age group of 31 to 35 years was most frequently infected with at least one of the viruses (22.8\%).

Forty of the $64 \mathrm{HBsAg}$ positive women were co-infected with HDV (4.0\%) in Group 1. Rates of other HBV infection markers were $23.6 \%$ for anti-HBs, $8.2 \%$ for $\mathrm{HBeAg}$, $18.1 \%$ for anti-HBe and $34.5 \%$ for anti-HBc (Table 4 ).

\section{IV) HIV Type 1 Genetic Diversity}

Analysis of $40 \mathrm{HIV}-1$ protease-reverse transcriptase sequences revealed a broad genetic diversity dominated by recombinant variants (84\%), with the CRF02_AG variant most commonly detected (50\%) (Fig. 1). Apart from CRFs and CRF-containing recombinants, recombinants of subtypes along the protease-reverse transcriptase region $\mathrm{A} / \mathrm{G}(6 \%), \mathrm{D} / \mathrm{F}(2 \%)$ and $\mathrm{K} / \mathrm{A}(4 \%)$ were also identified.

\section{V) Frequency of HIV-1 Drug Resistance-associated Mutations}

Mutations-associated to resistance to NRTI, NNRTI and PI were detected in 9 out of 40 specimens $(22.5 \%)$ (Table 5).

Some commonly identified RAMs to NRTIs include M184 V (12.5\%) and K70R (10\%), and to NNRTIs were K103 N (12.5\%) and Y181C (10\%), and to PIs M46 L (2.5\%) and L90 M (2.5\%) (Table 5).

Most of the women (62\%) had CD4 counts > 350 cells/ ul (mean $374+/-114$ cells $/ \mathrm{mm}^{3}$ ). HIV-1 plasma RNA viral load of $<1000$ copies $/ \mathrm{ml}$ was reported for 10 participants (25\%), while 6 (15\%) had greater than 10,000 copies/ml. The median viral load was 4378 copies/ml (IQR: 2036-8268 copies $/ \mathrm{ml}$ ). The greatest proportion of the study subjects (68\%) had viral load values between 1000 and 10,000 copies/ml. 
Table 4 Seroprevalence of HIV-1, HBV, HCV and HDV among Pregnant Women

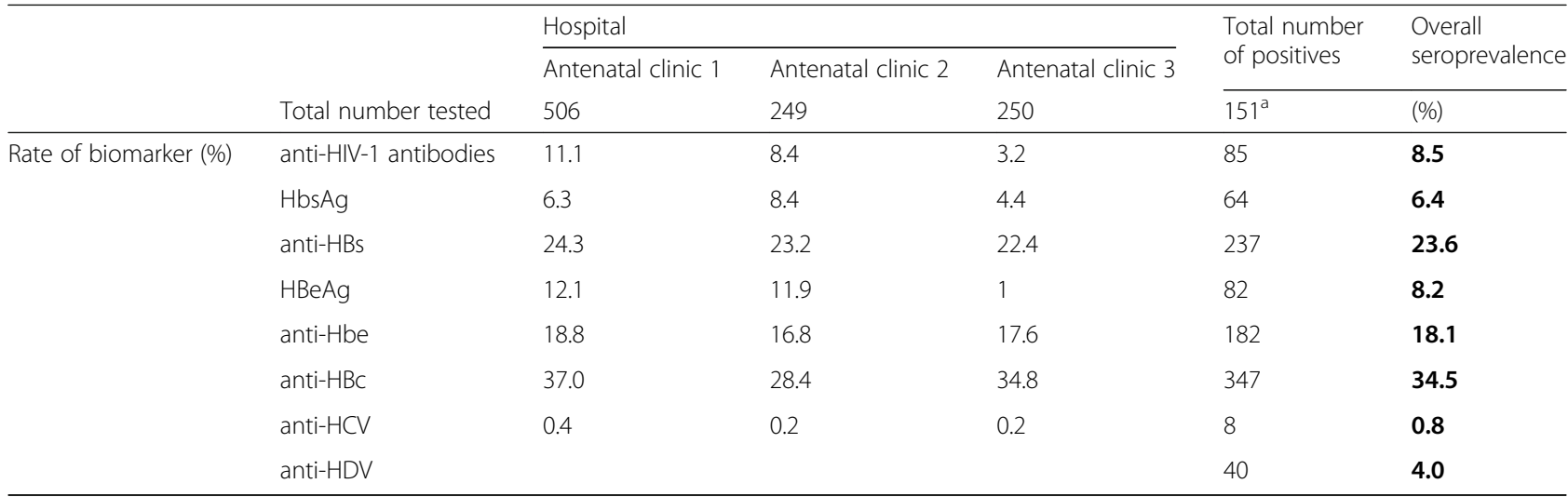

${ }^{\mathrm{a}}$ Total number of women infected with HIV, HBV or HCV

\section{Discussion}

Viruses in pregnant women and their impact on the outcome of the pregnancy and infant health have not been well-studied in the era of PMTCT in Cameroon just as in several sub Saharan African countries. We found in this study that $63.8 \%$ of the HIV-infected pregnant women knew their status before pregnancy, whilst none of the HCV-infected individuals and $5.9 \%$ of the HBsAg-positive, respectively, admitted that they had known their status before pregnancy. On the other hand, we found $8.2 \%$ rate of $\mathrm{HBeAg}$, a risk factor of transmission of HBV from mother-to-child [18]. As declared in the Bordeaux Call of April 2018 [19], WHO estimates that 0.3 and $6 \%$ of people infected with $\mathrm{HBV}$ and $\mathrm{HCV}$, respectively, know their serologic status in Africa. The marked difference in awareness of the serologic status, between HIV-infected pregnant women and those

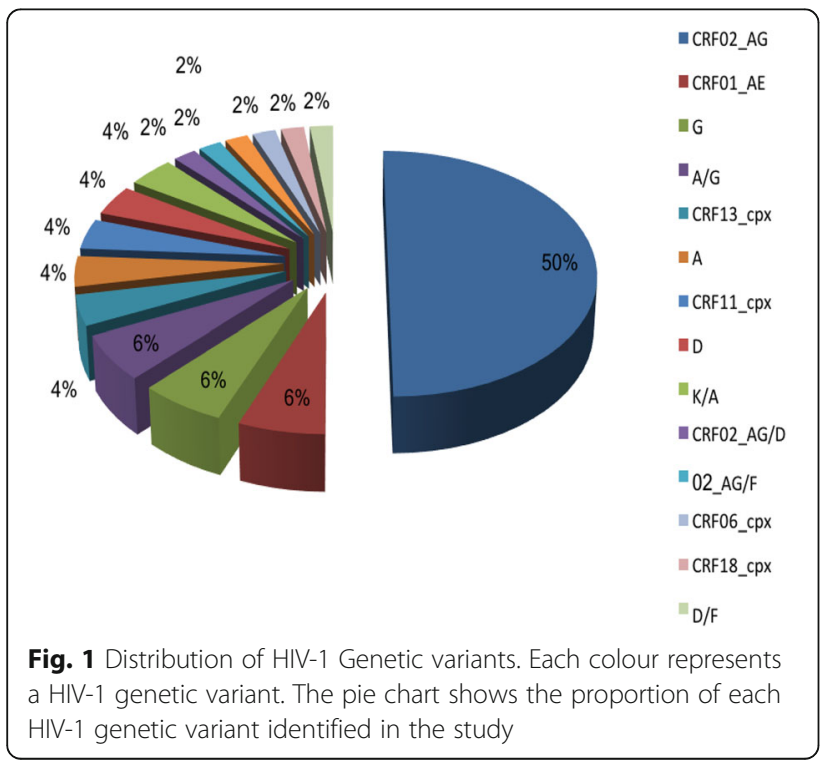

infected with the other viruses highlights the need to promote screening of HBV, HCV and HDV in women.

We report in this study that $47.8 \%$ of the pregnant women reported sexual intercourse as a route of $\mathrm{HBV}$ transmission while $47.1 \%$ reported the vertical transmission route. Although $83.3 \%$ of the study population reported that vaccination against hepatitis $B$ would reduce the risk of transmission of $\mathrm{HBV}$, only $2.5 \%$ of the women reported haven been vaccinated. The seroprevalence of HIV in our study was $8.5 \%$ higher than that reported in the Demographic and Health Survey (DHS) of $7.6 \%$ in 2011 [20].

Only one woman was infected with $\mathrm{HCV}$ in our study $(0.98 \%)$, a rate which is low compared to that of $\mathrm{HBV}$ or HIV-1, although Ndumbe and colleagues reported a higher rate in Yaounde of 5.5, and 6.0\% in a rural community in the South West Region of Cameroon [21]. However, higher prevalence was found among pregnant women in bigger cities like in Benin City in Nigeria of $3.6 \%$ [22]. The co-infection rate of $\mathrm{HIV} / \mathrm{HBV}$ in this study was $0.5 \%$. This was lower when compared to $9.3 \%$ reported by Kfutwah et al. among pregnant women in Yaounde with known HIV status [23], and 7.4\% in the general population in Cameroon [24].

Antiretroviral drug resistance testing is rarely used to follow-up HIV-infected pregnant women nor infants on ART in Cameroon. A few studies have been carried out in Cameroon to determine the levels of antiretroviral drug resistance in different populations [25-31], but little has been done on HIV-1 infected women during and after pregnancy. Our study was carried out on samples from $40 \mathrm{HIV}$-infected and breastfeeding women with the goal to evaluate the pattern of ARV drug resistance in women enrolled in the PMTCT Programme and who were breastfeeding.

The prevalence of antiretroviral drug resistance in this study was $22.5 \%$ (9/40). This is higher than the findings of Boghuma and colleagues [32] who evaluated ARV 
Table 5 Frequency of HIV-1 Mutations associated to Resistance to different Classes of Antiretroviral (ARV) Drugs

\begin{tabular}{|c|c|c|c|c|c|c|c|c|}
\hline \multicolumn{3}{|c|}{ Nucleo(s)tide reverse transcriptase inhibitors (NRTI) } & \multicolumn{3}{|c|}{ Non nucleoside reverse transcriptase inhibitors (NNRTI) } & \multicolumn{3}{|c|}{ Protease inhibitors (PI) } \\
\hline Major RAM & Number & Frequency (\%) & Major RAM & Number & Frequency (\%) & Major RAM & Number & Frequency (\%) \\
\hline M184V & 5 & 12.5 & K103N & 5 & 12.5 & M46L & 1 & 2.5 \\
\hline K70R & 4 & 10 & YI8IC & 4 & 10 & L90 M & 1 & 2.5 \\
\hline $\mathrm{T} 215 \mathrm{Y}$ & 3 & 7.5 & $\mathrm{Yl} \mid 88 \mathrm{~L} / \mathrm{H} / \mathrm{C}$ & 2 & 5 & & & \\
\hline V75 M & 3 & 7.5 & $\mathrm{H} 221 \mathrm{Y}$ & 2 & 5 & & & \\
\hline $\mathrm{T} 215 \mathrm{~F}$ & 2 & 5 & $\mathrm{P} 225 \mathrm{H}$ & 1 & 2.5 & & & \\
\hline L201 W & 2 & 5 & $F 227 \mathrm{~L}$ & 1 & 2.5 & & & \\
\hline M41 L & 2 & 5 & K238 T & 1 & 2.5 & & & \\
\hline L74 V & 1 & 2.5 & & & & & & \\
\hline K219Q/E & 1 & 2.5 & & & & & & \\
\hline K65R & 1 & 2.5 & & & & & & \\
\hline
\end{tabular}

drug resistance in a group of Cameroonian women at 6-8 weeks after delivery and found 4 out of $31(12.9 \%)$ with ARV drug resistant HIV-1. This indicates that ARV drug resistance in women enrolled in the PMTCT Programme in Cameroon may actually be growing following the increasing access to ART. We could however not explain this trend because the ARV drug resistance profile of these women prior to ARV exposure was not known.

Other studies have shown variable levels of drug resistance in HIV-infected women following the PMTCT Programme. The women in this study were exposed to NRTIs and NNRTIs. Of the 40 women, only $6(15.0 \%)$ harboured HIV-1 variants with major mutations associated to NRTI resistance. Of the nine mutations, M184 V (12.5\%) and K70R (10.0\%) were most frequently identified. The M184 V is known to confer high levels of resistance to lamivudine (3TC) and emtricitabine (FTC), while K70R is known to confer intermediate levels of resistance to zidovudine (AZT). The high frequency of M184 V found in our study could be explained by the fact that lamivudine and zidovudine are part of PMTCT regimens in Cameroon. Meanwhile, 5 women out of 40, harboured mutations that confer resistance to NNRTIs of which $\mathrm{K} 103 \mathrm{~N}$ (12.5\%) and Y181C (10.0\%) were the most frequent. Of the 9 RAMs identified, K103 $\mathrm{N}$ was identified in 5 women, which predicts resistance to nevirapine. Y181C as well as $\mathrm{K} 103 \mathrm{~N}$ confer intermediate to high level resistance to nevirapine and efavirenz, two NNRTIs commonly used in Cameroon.

On the other hand, two women were found with RAMs to protease inhibitors which were M46 L (2.5\%) and L90 M (2.5\%). The frequency of PI mutations unlike that of NRTI and NNRTI was low in our study. This could be explained by the fact that PIs are rarely used in Cameroon, and are reserved for patients failing first line regimens which contain two NRTIs and one NNRTI. None of the participants in our study had been exposed to PI, therefore, this could have been a case of transmitted PI resistance. We report a broad genetic diversity in our study dominated by recombinant variants (84\%). The most represented HIV-1 subtype in our study population was CRF02_AG (50\%), similar to the findings reported from other studies [14, 28, 31]. However, we could not determine the HBV, HCV and HDV genetic variants as well as the antiviral drug resistance pattern due to limited resources. Furthermore, we could not follow-up the infants born to virus-positive mothers to determine the rates of vertical transmission.

\section{Conclusions}

The rates of HBV and HIV-1 infection among pregnant women indicate that if effective prevention interventions are not offered, and sensitization of pregnant women on vertically transmissible viruses is not promoted, then we cannot fully protect the next generation of children from these infections. The frequency of HIV-1 drug resistance is high among breastfeeding women after 6 weeks postpartum. Therefore, drug resistance testing should be used to guide the choice of ART for infants who become infected by their mothers enrolled in the PMTCT Programme. The missing link therefore is the policy of screening pregnant women for other communicable diseases that can be transmitted from mother-to-child, and expand the PMTCT Programme in Cameroon. Bridging this gap is a priority and contribution to the WHO Hepatitis Elimination Initiative in a LMIC.

\section{Additional file}

Additional file 1: Questionnaire, KAP Survey among pregnant women on transmission and prevention of Hepatitis B virus. (DOCX $37 \mathrm{~kb}$ )

\section{Abbreviations}

3TC: Lamivudine; AIDS: Acquired Immunodeficiency Syndrome; ANC: Antenatal Care; Anti HBC: Anti Hepatitis B core antibodies; ART: Antiretroviral treatment; AZT: Zidovudine; CD4: Cluster of Differentiation; CRF: Circulating Recombinant Form; DHS: Demographic and Health Survey; DNA: Deoxyribonucleic acid; 
EID: Early Infant Diagnosis; ELISA: Enzyme linked Immunosorbent Assay; FTC: Emtricitabine; HBeAg: Hepatitis B envelope antigen; HBsAg: Hepatitis B surface Antigen; HBV: Hepatitis B Virus; HCV: Hepatitis C Virus; HDV: Hepatitis D Virus; HIV: Human Immunodeficiency Virus; IRB: Institutional Review Board; LMIC: Low- and Middle- Income Countries; NACP: National AIDS Control Programme; NNRTI : Non nucleoside reverse transcriptase inhibitors; NRTI: Nucleoside or nucleotide reverse transcriptase inhibitors; NVP: Nevirapine; PI: Protease Inhibitors; PMTC: Prevention of Mother to Child Transmission; RNA: Ribonucleic acid; STD: Sexually transmitted diseases

\section{Acknowledgements}

The women who participated in the study, and all the hospital staff and who assisted in data collection.

\section{Funding}

Funding for the research was provided by the Chantal Biya International Reference Centre for Research on Prevention and Management of HIV/AIDS (CIRCB), Yaounde, Cameroon. The CIRCB staff were involved in designing the study, data collection, analysis and interpretation as well as writing of the manuscript.

\section{Availability of data and materials}

The datasets used and/or analyzed during the current study are available from the corresponding author on reasonable request.

\section{Authors' contributions}

JNT, AN and RM designed the study, analyzed and interpreted data, and prepared the manuscript. WT contributed to the project design, administration of Informed Consent Form, carried out physical examination of the pregnant women to be recruited in the study, data entry, management of project at Antenatal Clinic 1, and review of manuscript. CKK contributed in the study design, counselling of mothers and follow-up of infants born of virus-infected mothers in Antenatal Clinic 1, data analysis, and review of manuscript. AJN contributed in administration of the Informed Consent Form and Questionnaire, carried out physical examination of the pregnant women, supervision of blood specimen collection from pregnant women at Antenatal Clinic 2, processing and testing of specimens for HIV-1, HBV, HCV and HDV infection, data entry and analysis, and preparation of the manuscript. KN contributed in administration of the Informed Consent Form and Questionnaire, carried out physical examination of the pregnant women, supervision of blood specimen collection from pregnant women at Antenatal Clinic 3, processing and testing of specimens for HIV-1, HBV, HCV and HDV infection, data entry and analysis, and preparation of the manuscript. KA contributed to the administration of the Informed Consent Form and Questionnaire, supervision of blood specimen collection from HIV-infected and breastfeeding women, processing and testing of specimens, interpretation of HIV drug resistance data, data entry and analysis, and preparation of the manuscript. SM contributed to the study design, result notification and counselling of the virus-positive women, data validation, and review of manuscript. DT and SS performed laboratory data analyses, and ID analyzed the data. All authors have read and approved the manuscript.

\section{Author's information}

JNT is an Associate Professor of Molecular Biology and Chair of Department of Biochemistry, and Coordinator of Laboratories in CIRCB who contributed in setting up the Early Infant Diagnosis HIV Programme in Cameroon in 2007; RM (Professor) is a gynaecologist and Director of the Division of Family Health in the Ministry of Public Health; WT (Senior Lecturer) is a gynaecologist, and CKK (Senior Lecturer) is a paediatrician; AJN, KN, KA and SM are clinicians; AN, DT and SS are biologists and ID is a biostatistician.

\section{Ethics approval and consent to participate}

Approval to carry out this work was given by the Chantal Biya International Reference Centre (CIRCB) Institutional Review Board (IRB), Yaounde, Cameroon. A written informed consent was given by each woman before participation. The laboratory results were given to the women and those who were positive for any of the virus, were referred to care services.

\section{Consent for publication}

Not applicable.

\section{Competing interests}

The authors declare that they have no competing interests.

\section{Publisher's Note}

Springer Nature remains neutral with regard to jurisdictional claims in published maps and institutional affiliations.

\section{Author details}

${ }^{1}$ Chantal Biya International Reference Centre for Research on Prevention and Management of HIV/AIDS (CIRCB), Molecular Biology Laboratory, B.P. 3077, Messa, Yaounde, Cameroon. ${ }^{2}$ Chantal Biya International Reference Centre for Research on Prevention and Management of HIV/AIDS (CIRCB), Laboratory of Immunology and Microbiology, Yaounde, Cameroon. ${ }^{3}$ Faculty of Health Sciences, University of Bamenda, Bamenda, Cameroon. ${ }^{4}$ Faculty of Medicine and Biomedical Sciences, University of Yaounde I, Yaounde, Cameroon.

${ }^{5}$ Faculty of Health Sciences, University of Montagnes, Bangangte, Cameroon. ${ }^{6}$ Chantal Biya International Reference Centre for Research on Prevention and Management of HIV/AIDS (CIRCB), Data Analysis and Impact Studies Unit, Yaounde, Cameroon. ${ }^{7}$ Chantal Biya International Reference Centre for Research on Prevention and Management of HIV/AIDS (CIRCB), Medical Unit, Yaounde, Cameroon. ${ }^{8}$ Chantal Biya International Reference Centre for Research on Prevention and Management of HIV/AIDS (CIRCB), Clinical Diagnostics Laboratory, Yaounde, Cameroon.

Received: 5 June 2018 Accepted: 26 November 2018 Published online: 22 December 2018

\section{References}

1. UNAIDS 2017 Progress Report. www.unaids.org/en/resources.

2. Ducancelle A, Abgueguen P, Birguel J, Mansour W, Pivert A, Le GuillouGuillemette H, Sobnangou JJ, Rameau A. High Endemicity and Low Molecular Diversity of Hepatitis B Virus Infections in Pregnant Women in a Rural District of North Cameroon. PloS one. 2013;8(11):e80346.

3. Fomulu NJ, Morfaw FL, Torimiro JN, Nana P, Koh MV, William T. Prevalence, correlates and pattern of hepatitis B among antenatal clinic attenders in Yaounde-Cameroon: is perinatal transmission of HBV neglected in Cameroon? BMC Pregnancy Childbirth. 2013;13:158.

4. Hong-Lin Chen, Man-Li Zha, Ji-Yu Cai, Gang Qin. 2018. Maternal Viral Load and hepatitis B virus mother-to-child transmission risk: A Systematic Review and Meta-analysis. https://doi.org/10.1111/hepr.13072

5. Wong VCW, Lee AKY, Ip HMH. Transmission of hepatitis $B$ antigens from symptom free carrier mothers to the fetus and the infant. BJOG. 1980;87(11): 958-65.

6. Ducancelle A, Abgueguen P, Birguel J, Mansour W, Pivert A, Le GuillouGuillemette H, Sobnangou JJ, Rameau A, Huraux JM, Lunel-Fabiani F. High endemicity and low molecular diversity of hepatitis B virus infections in pregnant women in a rural district of North Cameroon. PLoS One. 2013; 8(11):e80346. https://doi.org/10.1371/journal.pone.0080346.

7. Torimiro J, Monamele GC, Kowo MP, Takou D, Pouokam G-B, Fokam J, Njoya O. Co-infection of. Hepatitis B Virus and Hepatitis Delta Virus in YaoundeCameroon Judith Ndongo British Microbiology Research Journal. 2014;4(12): 1381-91.

8. WHO Progress Report 2015. https://www.who.int/gho/publications/world_ health_statistics/2015/en/.

9. Ministry of Public Health Progress Report 2015.

10. Ayouba A, Le Fouler L, Lien TTX, Ly N, Maréchal V, Véssière A, Kfutwah A, Reynes JM, Menu E, Nerrienet E, Vray M, Fleury H, Barré-Sinoussi F. Prevalence of HIV-1 drug resistance mutations in antiretroviral naïve pregnant women from Cambodia, Cameroon, Central African Republic and Vietnam. Retrovirology. 2008;5(Suppl 1):018. https://doi.org/10.1186/17424690-5-S1-018

11. Sagnia B, Ateba Ndongo F, Ndiang Moyo Tetang S, Ndongo Torimiro J, Cairo C, Domkam I, Agbor G, Mve E, Tocke O, Fouda E, Ouwe Missi OukemBoyer O, Colizzi V. Reference values of lymphocyte subsets in healthy, HIVnegative children in Cameroon. Clin Vaccine Immunol. 2011;18(5):790-5.

12. https://www.molecular.abbott/int/en/products/infectious-disease/realtimehiv-1-viral-load. Accessed 25 May 2018.

13. https://www.qiagen.com/us/shop/sample-technologies/rna/viral-rna/ qiaamp-viral-rna-mini-kit/\#orderinginformation. Accessed 25 May 2018.

14. Fokam J, Salpini R, Santoro MM, Cento V, D'Arrigo R, Gori C, Perno CF, Colizzi V, Nanfack A, Gwom LC, Cappelli G, Takou D. Performance evaluation 
of an in-house human immunodeficiency virus type-1 protease-reverse transcriptase genotyping assay in Cameroon. Arch Virol. 2011;156:1235-43.

15. http://www3.appliedbiosystems.com/cms/groups/mcb_support/documents/ generaldocuments/cms_041468.pdf. Accessed 25 May 2018.

16. https://www.hiv.lanl.gov/content/index. Accessed 25 May 2018.

17. https://hivdb.stanford.edu/hivdb/by-sequences/. Accessed 30 March 2018.

18. Andersson MI, Rajbhandari R, Kew MC, Vento S, Preiser W, Hoepelman AIM, Theron G, Cotton M, Cohn J, Glebe D, Lesi O, Thursz M, Peters M, Chung R, Wiysonge C. Mother-to-child transmission of hepatitis B virus in sub-Saharan Africa: time to act. Lancet Global Health. 2015;3:e358-9.

19. Bordeaux Call 2018 for the Fight against Viral Hepatitis B and C (http:// www.afravih2018.org/appel-de-bordeaux). Accessed 19 May 2018.

20. Ministry of Public Health Progress Report 2011.

21. Ndumbe PM, Skalsky J. Hepatitis C virus infection in different populations in Cameroon. Scand J Infect Dis. 1993;25(6):689-92

22. Ugbebor O, Aigbirior M, Osazuwa F, Enabudoso E, Zabayo O. The prevalence of hepatitis $B$ and $C$ viral infections among pregnant women. $N$ Am J Med Sci. 2011;3(5):238-41.

23. Kfutwah AK, Tejiokem MC, Njouom R. A low proportion of HBeAg among HBsAg-positive pregnant women with known HIV status could suggest low perinatal transmission of HBV in Cameroon. Virol J. 2012;9:62.

24. Laurent C, Bourgeois A, Mpoudi M, Butel C, Mpoudi-Ngolé E, Delaporte E. HIV and hepatitis C virus coinfection, Cameroon. Emerg Infect Dis. 2007; 13(3):514-6.

25. Fonjungo PN, Mpoudi EN, Torimiro JN, Alemnji GA, Eno LT, Lyonga EJ, Nkengasong JN, Lal RB, Rayfield M, Kalish ML, Folks TM, Pieniazek D. Human immunodeficiency virus type 1 group $m$ protease in Cameroon: genetic diversity and protease inhibitor mutational features. J Clin Microbiol. 2002; 40(3):837-45.

26. Vessière $A$, Nerrienet $E$, Kfutwah $A$, Menu $E$, Tejiokem $M$, Pinson-Recordon $P$, Barré-Sinoussi F, Fleury H, Ayouba A. HIV-1 pol gene polymorphism and antiretroviral resistance mutations in drug-naive pregnant women in Yaoundé, Cameroon. JAIDS. 2006;42(2):256-8.

27. Burda ST, Viswanath R, Zhao J, Kinge T, Anyangwe C, Tinyami ET, Haldar B, Powell RLR, Jarido V, Hewlett IK, Nyambi PN. HIV-1 reverse transcriptase drug-resistance mutations in chronically infected individuals receiving or Naïve to HAART in Cameroon. J Med Virol. 2010:82(2):187-96.

28. Courtney CR, Agyingi L, Fokou A, Christie S, Asaah B, Meli J, Ngai J, Hewlett I, Nyambi PN. Monitoring HIV-1 Group M Subtypes in Yaoundé, Cameroon Reveals Broad Genetic Diversity and a Novel CRF02_AG/F2 Infection. AIDS Res Hum Retrovir. 2016;32(4):381-5.

29. Ikomey GM, Assoumou MCO, Gichana JO, Njenda D, Mikasi SG, Mesembe M, Lyonga $\mathrm{E}$, Jacobs GB. Observed HIV drug resistance associated mutations amongst naïve immunocompetent children in Yaoundé, Cameroon. Germs. 2017. Dec. 2017;7(4):178-85.

30. Nanfack AJ, Redd AD, Bimela JS, Ncham G, Achem E, Banin AN, Kirk Patrick AR, Porcella SF, Agyingi LA, Meli J, Colizzi V, Nádas A, Gorny MK, Nyambi PN, Quinn TC, Duerr R. Multimethod Longitudinal HIV Drug Resistance Analysis in ART Naive Patients; 2017. https://doi.org/10.1128/JCM.00634-17JCM. 00634-17.

31. Ceccarelli L, Salpini R, Moudourou S, Cento V, Santoro MM, Fokam J, Takou D, Nanfack A, Dori L, Torimiro J, Sarmati L, Andreoni M, Perno CF, Colizzi V, Cappelli G. Characterization of drug resistance mutations in naïve and ARTtreated patients infected with HIV-1 in Yaounde, Cameroon. J Med Virol. 2012;84(5):721-7.

32. Titanji B, Aasa-Chapman M, Pillay D, Jolly C. Protease inhibitors effectively block cell-to-cell spread of HIV-1 between T cells. Retrovirology. 2013;10:161. https://doi.org/10.1186/1742-4690-10-161.

Ready to submit your research? Choose BMC and benefit from:

- fast, convenient online submission

- thorough peer review by experienced researchers in your field

- rapid publication on acceptance

- support for research data, including large and complex data types

- gold Open Access which fosters wider collaboration and increased citations

- maximum visibility for your research: over $100 \mathrm{M}$ website views per year

At $\mathrm{BMC}$, research is always in progress.

Learn more biomedcentral.com/submissions 